\title{
36. SARGASSUM DESFONTAINESII (TURNER) C. AGARDH (FUCALES, FUCOPHYCEAE), PRIMERA CITA PARA EL MEDITERRÁNEO
}

\author{
Juan Antonio GONZÁLEZ GARCÍA y Francisco CONDE
}

Palabras clave. Sargassum desfontainesii, Mediterráneo, Marruecos.

En el curso de los trabajos que sobre macroflora marina se están realizando en las costas mediterráneas marroquíes desde Mayo de 1989, se ha constatado la presencia, en tres localidades del Cabo Tres Forcas, de Sargassum desfontainesii (Turner) C. Agardh, especie que no había sido citada con anterioridad en todo el mar Mediterráneo (cf. Ribera et al., 1992). El taxon es de orígen fitogeográfico atlántico tropical y Afonso et al., 1984 consideraban como límite septentrional de su distribución las Islas Madeira (cf. Piccone, 1884). También se halla en todas las Islas Canarias (Gil Rodríguez et al., 1984).

El material encontrado estaba siempre fructificado, observaba la siguiente corología y estado de reproducción (meses que figuran en cifras romanas): Cazaza, III, IV y V (MGC PHYC 2115); Punta Negri, IV, VI y VII; Cala Viñas, III, IV, V, VI y VII (MGC PHYC 2116) (Mapa 1).

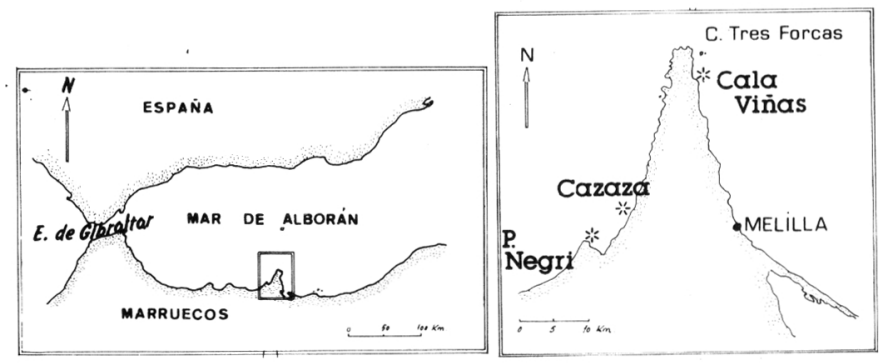

Mapa 1. Localización de Sargassum desfontainesii en el Mar Mediterráneo.

Las plantas aparecen siempre entremezcladas con grandes poblaciones infralitorales fotófilas de otras grandes fucales, mayoritariamente Sargassum vulgare C. Agardh y Cystoseira compressa (Esper) Gerloff et Nizamuddin, en fondos subhorizontales de ensenadas con aguas semiencalmadas y a profundidades siempre por encima de $2,5 \mathrm{~m}$.

Los ejemplares alcanzan tamaño cercano al metro, presentando cauloides compresos y ramificados, con típicos filoides bifurcados sin nerviación central patente; en las partes basales de las plantas, a veces, aparecen filoides más anchos con nervio central. Los aerocistos son múticos con pedicelos de hasta $6 \mathrm{~mm}$ de longitud. Los receptáculos son ramificados y de pequeño tamaño (1,5 $\mathrm{mm}$ a $4 \mathrm{~mm}$ x $0,5 \mathrm{~mm})$. (Lám. I). Toda la morfología está muy en consonancia con las descripciones que de esta especie hacen Agardh, 1823 y Gil Rodríguez et al., op. cit.

Si incluímos la cita de Libia de $S$. ramentaceum Zarmouh et Nizamuddin, 1991, a las siete especies de Sargassum que existen en el Mediterráneo, habría que añadir una octava: S. desfontainesii. 


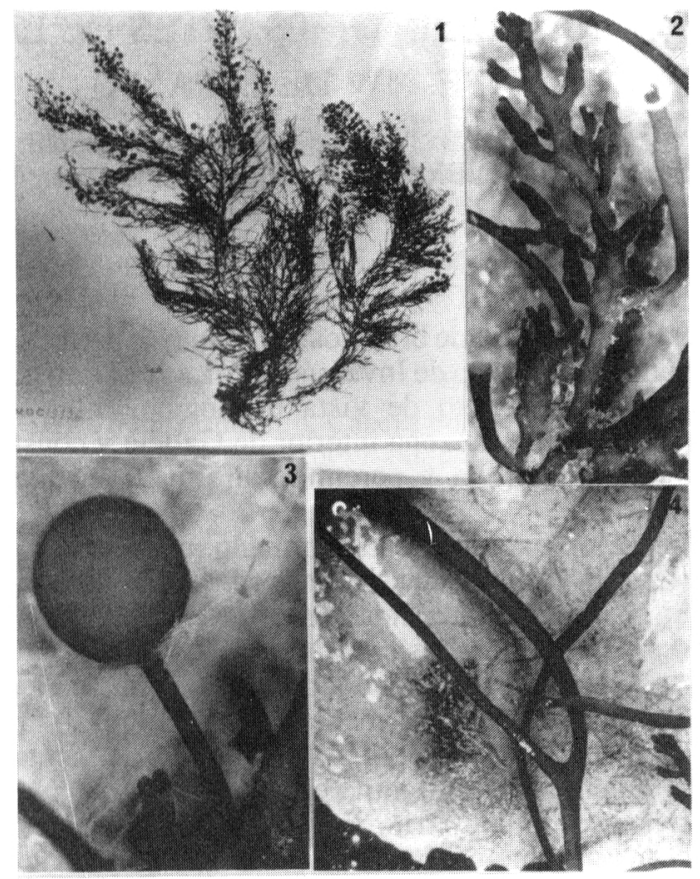

Lámina I. S. desfontainesii; estructuras reproductoras y vegetativas. 1: pliego del MGC PHYC 2116; 2: receptáculos; 3: aerocistos; 4: filoides bifurcados sin nerviación.

\section{BIBLIOGRAFÍA}

AFONSO, J., M.C. GIL RODRÍGUEZ, R. HAROUN, M. VILLENA y W. WILDPRET -1984Adiciones y correcciones al catálogo de las algas marinas bentónicas para el Archipiélago Canario. Vieraea, 13: 27-49.

AGARDH, C. -1823-Species Algarum rite cognitae cum synonymis differentiis specificis et descriptionibus succinctis. Volumen primum. Gryphiswaldiae.

GIL RODRÍGUEZ, M.C., J. AFONSO, R. HAROUN y W. WILDPRET - 1984- Iniciación al estudio taxonómico-ecológico del género Sargassum C. Agardh (Phaeophyta) en las Islas Canarias. Act. IV Symp. Benthos Marinho Lisboa, 3: 86-92.

PICCONE, A. -1884- Crociera del corsaro alle Isole Madera e Canarie del Capitano E. d'Albertis. Alghe $60 \mathrm{pp}$. Génova.

RIBERA, M.A., A. GÓMEZ GARRETA, T. GALLARDO, M. CORMACI, G. FURNARI \& G. GIACCONE -1992- Check-list of Mediterranean Seaweeds. I. Fucophyceae. Botanica Marina, 35: 109-130.

ZARMOUH, M. \& M. NIZAMUDDIN - 1991- Sargassum ramentaceum (Phaeophyta, Fucales), a new species from the eastern coast of Libya. Willdenowia, 21: 269-273.

(Aceptado para su publicación en Mayo de 1992)

Dirección de los autores. J.A. González García: E.U. Formación del Profesorad de E.G.B. Universidad de Granada. Melilla. F. Conde: Dpto. Biología Vegetal. Facultad de Ciencias. Universidad de Málaga. 29080 Málaga. 